\title{
Herpes Zoster Lesions on Reconstructed Breast Skin: Rare Objective Proof of Reinervation
}

\author{
Laurenz Weitgasser, Stephan Wolfgang Valina, Thomas Schoeller, Gudrun Ehebruster \\ Department of Hand-, Breast-, and Reconstructive Microsurgery, Marienhospital Stuttgart, Stuttgart, Germany
}

Blazed up Herpes zoster lesions have been described in very few patients after free and pedicled flap transfer for reconstructive purpose. Although sensory recovery after flap reconstructions has been studied extensively most studies addressed subjective perceptions of sensation. Objective investigations of spontaneous reinervation of free and pedicled flaps are rare. We would like to present a witnessed herpes zoster infection of a latissimus dorsi skin flap 2 years after breast reconstruction.

Keywords Herpes zoster / Latissimus dorsi / Breast reconstruction / Reinnervation

\author{
Correspondence: Laurenz Weitgasser \\ Department of Hand-, Breast-, and \\ Reconstructive Microsurgery \\ Marienhospital Stuttgart, Teaching \\ Hospital of the University of \\ Tuebingen, Boeheimstraße 37, 70199 \\ Stuttgart, Germany \\ Tel: +49-711-64890-7216 \\ Fax: +49-711-64890-8222 \\ E-mail: Laurenz.weitgasser@pmu. \\ ac.at
}

This article contains supplemental Video S1.

No potential conflict of interest relevant to this article was reported.

Received: 11 May 2016 • Revised: 11 Aug $2016 \bullet$ Accepted: 23 Aug 2016

pISSN: 2234-6163・elSSN: 2234-6171・ https://doi.org/10.5999/aps.2017.44.1.72・Arch Plast Surg 2017;44:72-75

\section{INTRODUCTION}

Reconstructive surgery with flaps is a well-established surgical treatment for various indications from head to toe. Sensory recovery after flap transfers has been addressed and investigated. However, the vast majority of concluded studies have analyzed patients subjective perceptions to touch, pain, temperature or pressure. Objective investigations on spontaneous reinervation are rare. In this report we would like to describe our experience in a case of blazed up herpes zoster lesions that developed in a denervated pedicled latissimus dorsi flap 2 years after breast reconstruction, proving spontaneous reinervaton of the priorly denervated flap. Only very few cases of herpes zoster infections in transverse abdominis flaps were reported so far [1-5]. To our knowledge this is the first report of a herpes zoster infection in a latissimus dorsi flap after breast reconstruction.

\section{CASE}

A 58-year-old who had her right breast reconstructed with a pedicled denervated latissimus dorsi flap and a silicone implant 2 years ago presented to our clinic with recurrent capsular fibrosis. Our treatment plan involved a Capsulectomy and volume reconstruction with a free deep inferior epigastric artery perforator flap. On the day of the in-patient admission the preoperative physical examination revealed a pruritic erythematous vesicular rash around the right trunk and the reconstructed right breast/latissimus dorsi skin flap. Skin lesions spread along the Th5 and Th6 dermatome of the right hemithorax (Figs. 1, 2) and pruritus and light pain were present. Neurologic counseling proved the suspected diagnosis of herpes zoster.

Sensory testing of both breasts was concluded to investigate the reinervation of the right reconstructed breast. Sensory test- 


\section{Fig. 1. Visible Herpes Zoster lesions}

Herpes zoster lesions on the right hemithorax in dermatomal distribution.
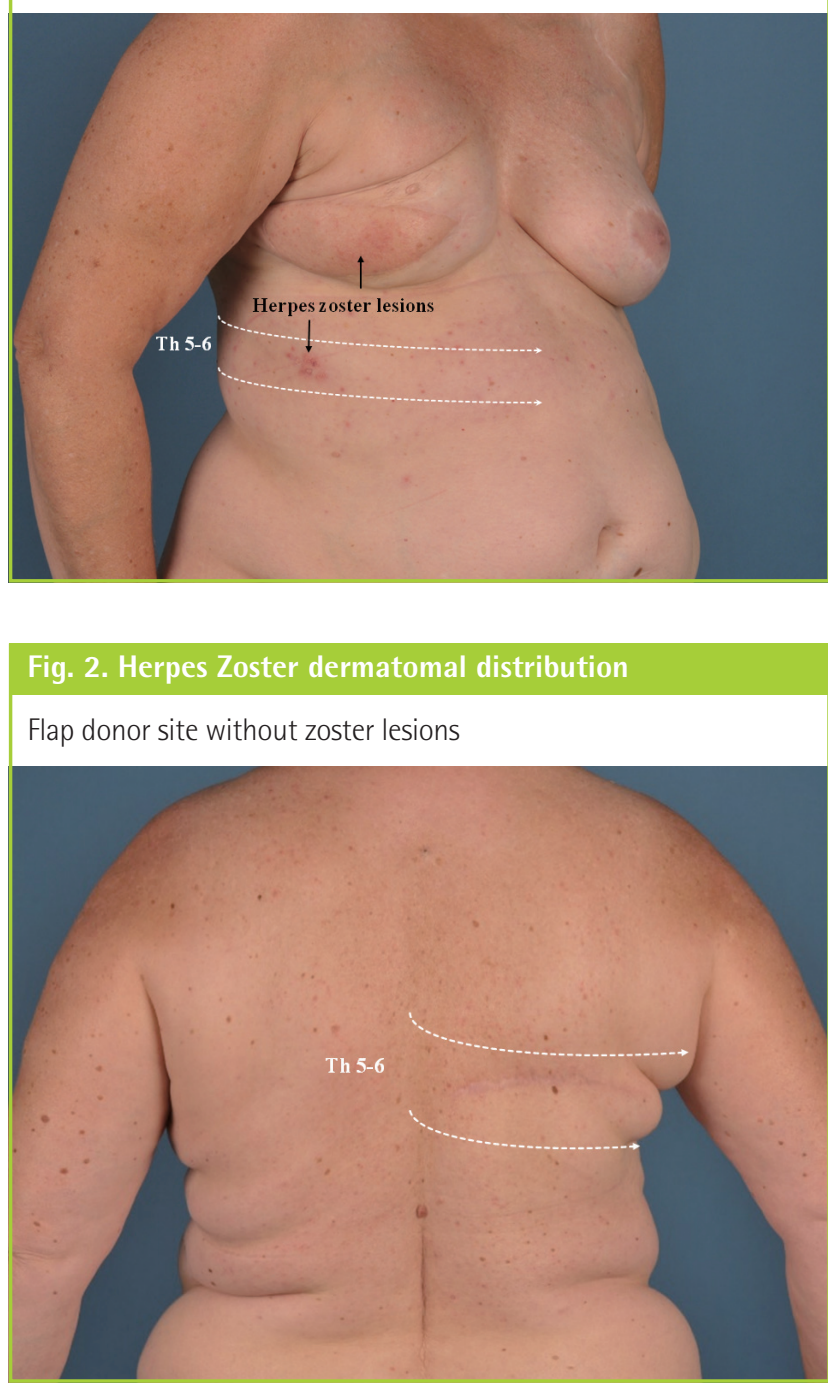

ing involved two-point discrimination and distinction of warm and cold sensation. Both breasts were examined in 13 defined areas each, oriented after the clock hands principle (Fig. 3).

The sensory examination revealed reduced general sensitivity in the reconstructed right- compared to the normal left breast. However besides an extensive certain numbness in the reconstructed breast, two-point discrimination as well as temperature distinction was present in major parts of the reconstructed breast (Fig. 4).

The planned surgery was then rescheduled, and our patient was dismissed and treated with daily oral $125 \mathrm{mg}$ Brivudin antiviral therapy for 7 days. In the follow-up clinical examinations progressive vanishing of the rash was seen and all skin lesions healed uneventful, without postherpatic neuralgia.

\section{Fig. 3. Two-Point-Discrimination ( $\mathrm{mm})$}

Two-Point-Discrimination measured at 13 different positions for each breast.

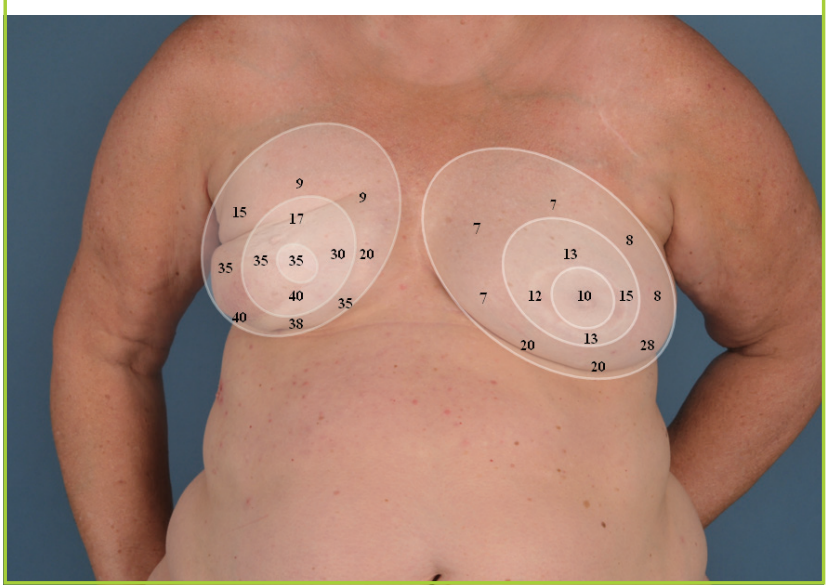

Fig. 4. Temperature testing

Red area, warm/cold distinction.

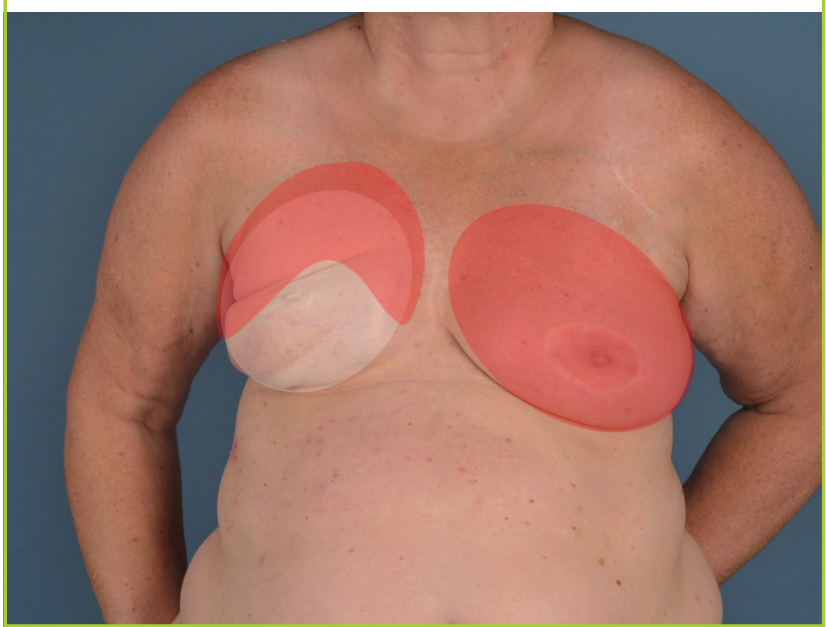

\section{DISCUSSION}

Multiple studies on spontaneous flap reinervation have been concluded, yet the actual mechanism behind is still controversial [6-9].

Lehmann et al. [8] examined flap reinervation after breast reconstructions. Their results showed that the sensibility by patients who underwent transverse rectus abdominal flaps was superior, objectively and subjectively, compared to latissimus dorsi breast reconstructions. Shridharani et al. [9] performed a systematical review of the literature on sensation after breast reconstruction and found that sensibility was considerably impaired in all patients and procedure independent. The sensation decreased in the following descending order. Best sensation was seen in deep inferior epigastric artery perforator flaps, followed 
by transverse rectus abdominis myocutaneous flap and later latissimus dorsi and finally implant-reconstructions. In one of the largest studies focussing on recovery of sensation after latissimus dorsi reconstruction, Tomita et al. [10] observed a negative effect in reinervation in larger preoperative breast size, older age and large body mass index value after breast conserving therapy and skin sparing mastectomy. Transferring sensate latissimus dorsi flaps for breast reconstruction by connecting the lateral cutaneous branch of the dorsal primary divisions of the seventh thoracic nerve, which controls sensation of the myocutaneous flap, with the lateral cutaneous branch of the fourth intercostal nerve which normally controls sensation of the breast demonstrated earlier recovery of sensation. In their small case series, Yano et al. [11] demonstrated a gradual recovery of sensation at about six months after surgery which reached the value of the normal healthy contralateral breast after about one year. In their control subjects the recovery was gradual after more than one year and reached the value of the normal side in only some of the control subjects. Similar results were seen in head and neck reconstructions with sensate myocutaneous latissimus dorsi flaps.

Yet, the authors observation of flap reinervation questions the time-benefit consideration of nerve coaptation due to the fact that the examined flap was reinervated anyhow. Exact mechanisms of reinervation and the role played by certain types of flaps is still under debate [8-11]. According to early research of Davies [12] and Kredel and Evans [13] the quality of resensibility depends on the type and quantity of sensory end orangs in the transferred tissue. Which, according to Lehman et al. [8], means that the transverse rectus abdominal flap (TRAM) flap would have a higher chance for reinervation compared to the latissimus dorsi flap, since the quantity of end organs (Schwann cells and axons) is higher in muscles of the abdominal region compared to the back. Whereas Delay et al. [6] concludes comparable results between latissimus dorsi and other autologous flap breast reconstructions. After primary varicella zoster virus infection and hematogenous dissemination, e.g., after chickenpox disease-the virus remains latent in the spinal or cranial sensory dorsal root ganglia. Similar to herpes simplex I and II latency and possible reoccurence, the varicella zoster virus can spread from the ganglion along the corresponding sensory nerve to the skin and cause localized painful or pruritic rash in a dermatomal distribution when the host's immune system fails to repress the virus, causing shingles [14].

In the described patient report, since the musculocutaneous latissimus dorsi flap had been denervated in terms of sensory and motoric innervation at its elevation, the virus is believed to have spread along the reinervated sensory nerves from the dor- sal ganglia, through the intercostal nerves further into the skin surrounding the flap. Spontaneous reinervation could be verified in our concluded sensory testing using the two-point and temperature discrimination. Since our sensory testing showed better results in the outer fringe of the reconstructed breast, it seems that in this case the spontaneous ingrowth of the sensory nerves more likely started from the skin margins of the flap, than from the deep surface of the mastectomy bed. Although studied extensively, the actual mechanism of flap reinervation is still unclear, but it is most likely that both mechanisms play their role and reinervation seems to come from the mastectomy as well as the skin margins surrounding the flap likewise [6,7]. Therefore Turkof et al. [15] emphasised the need for thorough scar debridement, especially after radiotherapy to facilitate axonal regrowth from the mastectomy bed and surrounding skin. In the attached movie, a volunary activation of the latissimus dorsi flap, which was formerly denervated is demonstrated which indicates motoric reinervation as well (Supplemental Video S1).

In general herpes infections associated with free flaps are rare. After our literature research in pubmed and medline for "flap and herpes zoster", "flap and zoster" and "flap and herpes", we were able to identify only four cases after breast reconstruction with rectus abdominis flaps [1-4]. The evidence for spontaneous reinervation by herpes zoster infection was recently discussed by Lee and Choi [5] who observed a herpes zoster infection of a rectus abdominis flap [12]. One case of varicella zoster virus infection in the form of primary chickenpox infection was reported in an anterolateral thigh flap only a few weeks after upper extremity reconstruction [5].

Next to four reports of herpes zoster lesions in rectus abdominis flaps, this seems to be the first report of a herpes zoster erruption in a reconstructed breast with a latissimus dorsi flap and silicone implant. We would like call attention to this rare event which implicates another objective proof of spontaneous flap reinervation, and encourage vigilance after breast reconstruction to offer early treatment for these extraordinary cases.

\section{ORCID}

Laurenz Weitgasser http://orcid.org/0000-0001-9629-2228

\section{REFERENCES}

1. Tomita K, Inoue K. Cutaneous reinnervation of the rectus abdominis musculocutaneous flap after chest wall reconstruction: development of herpes zoster in the transplanted musculocutaneous flap. Ann Plast Surg 1998;41:191-3.

2. Lee JH, Ahn HC, Chung MS. Herpes zoster in a free trans- 
verse rectus abdominis myocutaneous flap after delayed breast reconstruction: evidence of spontaneous reinnervation. Ann Plast Surg 2015;74:693-4.

3. Skoll PJ, Hudson DA. Zoster following immediate transverse rectus abdominis myocutaneous breast reconstruction. Plast Reconstr Surg 2000;106:1218-9.

4. Tuchman M, Weinberg JM. Monodermatomal herpes zoster in a pseudodisseminated distribution following breast reconstruction surgery. Cutis 2008;81:71-2.

5. Lee JH, Choi HJ. Rare Varicella zoster virus infection in an ALT free flap. Int Wound J 2016;13:1052-3.

6. Delay E, Jorquera F, Lucas R, et al. Sensitivity of breasts reconstructed with the autologous latissimus dorsi flap. Plast Reconstr Surg 2000;106:302-9.

7. Yano K, Matsuo Y, Hosokawa K. Breast reconstruction by means of innervated rectus abdominis myocutaneous flap. Plast Reconstr Surg 1998;102:1452-60.

8. Lehmann C, Gumener R, Montandon D. Sensibility and cutaneous reinnervation after breast reconstruction with musculocutaneous flaps. Ann Plast Surg 1991;26:325-7.

9. Shridharani SM, Magarakis M, Stapleton SM, et al. Breast sensation after breast reconstruction: a systematic review. J Reconstr Microsurg 2010;26:303-10.

10. Tomita K, Yano K, Hosokawa K. Recovery of sensation in immediate breast reconstruction with latissimus dorsi myocutaneous flaps after breast-conservative surgery and skinsparing mastectomy. Ann Plast Surg 2011;66:334-8.

11. Yano K, Hosokawa K, Takagi S, et al. Breast reconstruction using the sensate latissimus dorsi musculocutaneous flap. Plast Reconstr Surg 2002;109:1897-902.

12. Davies L. The return of sensation to transplanted skin. Surg Gynecol Obstet 1934;59:533.

13. Kredel FE, Evans JP. REcovery of sensation in denervated pedicle and free skin grafts. Arch Neurol Psychiatry 1933; 29:1203-21.

14. Baird NL, Yu X, Cohrs RJ, et al. Varicella zoster virus (VZV)-human neuron interaction. Viruses 2013;5:210615.

15. Turkof E, Jurecka W, Sikos G, et al. Sensory recovery in myocutaneous, noninnervated free flaps: a morphologic, immunohistochemical, and electron microscopic study. Plast Reconstr Surg 1993;92:238-47.

Supplemental Video S1. Voluntary actiation of the formerly denervated Latissimus dorsi flap.

Supplemental data can be found at: http://e-aps.org/src/sm/aps-44-72-s001.wmv 